\title{
Mining activity in Nevada, 1851-1995
}

By Lorre A. Moyer

\section{U.S. Geological Survey Open-File Report 2004-1244}




\section{Table of Contents}

Abstract

Introduction

Acknowledgments

Overview of Data Files..

How to Run the Digital Movie.

Symbolization, Legends, Charts and Frame Layout.

Data Sources and Processing

Figure 1. The movie selection menu.

\section{List of Figures}

Figure 2. The return to the main movie button............................................................ 7

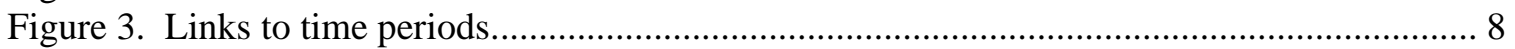

Figure 4. Return to the Links to decade time periods............................................................... 9

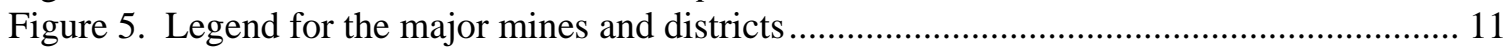

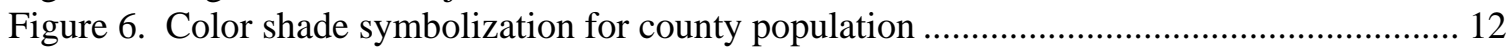

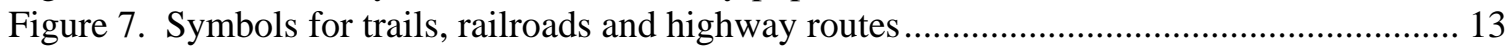

Figure 8. Production bar chart for industrial minerals, base metals, and precious metals. .......... 14

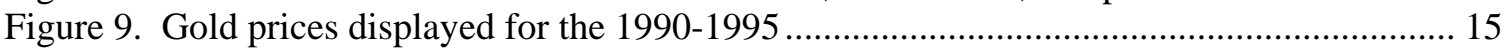

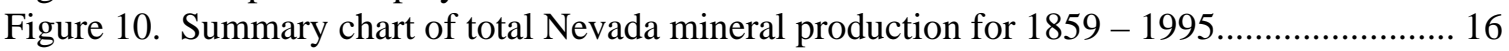

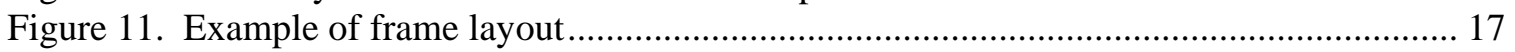

List of Tables

Table 1. List of PowerPoint files and metadata files 


\section{Abstract}

This report describes a Microsoft PowerPoint digital movie package that displays patterns of Nevada mineral activity from 1851 to 1995 and historical factors that influenced these patterns. The digital package consists of a full length educational movie with text and two short animations showing the evolving patterns of significant Nevada mineral deposits and mining districts over selected decades. The movie was created from images that were exported from a geographic information system (GIS), Environmental Systems Research Institute (ESRI) ArcView 3.2.

\section{Introduction}

The digital movie package, available online at http://pubs.usgs.gov/of/2004/1244/, was designed to serve educational purposes as well as draw interest when used in a display booth venue. The main PowerPoint movie file, movie.ppt, includes links to the two selflooping short animation subsets: mines + routes.ppt and districts + routes.ppt which are faster-paced overviews of the mineral deposit and mining district patterns. The short animations could be used to run continuously at events such as trade shows to encourage questions from passers-by. Spatial data for significant precious, base metal and industrial mineral deposits, as well as Nevada mining districts, were extracted from several sources that were queried for time periods of production activity. ESRI ArcView 3.2 software was used to create shapefiles and combine mineral-related data with other data types such as transportation routes, population trends, and major historical events, which were then displayed by decade in ArcView layouts and exported as JPEG formatted images for animation.

\section{Acknowledgments}

The author appreciates the assistance of Joe Tingley, Nevada Bureau of Mines and Geology, for providing unpublished annual production totals by county for Nevada precious metal, base metal and industrial mineral production. Gary Raines, U.S. Geological Survey, Reno, was instrumental in providing input on the movie design. 


\section{Overview of Data Files}

The digital movie package and metadata are provided in several files that are listed and briefly described in table 1 . The metadata files provide very detailed descriptions of the spatial data that was used in a formal format defined by the Federal Geographic Data Committee (FGDC). Metadata include data sources (lineage), data quality, and data processing procedures.

Table 1. List of PowerPoint files and metadata files provided in this publication

\begin{tabular}{ll}
\hline File Name & File Description \\
\hline movie.ppt & \multicolumn{1}{c}{ Movie Files } \\
mines+routes.ppt & $\begin{array}{l}\text { Microsoft PowerPoint file format for full movie of mining } \\
\text { activity in Nevada 1851-1995. }\end{array}$ \\
& $\begin{array}{l}\text { Microsoft PowerPoint file format for looped short animatio } \\
\text { mine and route patterns in Nevada 1851-1995. }\end{array}$ \\
districts+routes.ppt & $\begin{array}{l}\text { Microsoft PowerPoint file format for looped short animatio } \\
\text { mining district and route patterns in Nevada 1851-1995. }\end{array}$ \\
\hline metadata.htm & \multicolumn{1}{c}{ Formal Metadata } \\
& $\begin{array}{l}\text { Federal Geographic Data Committee "hypertext markup } \\
\text { language" (FGDC HTML) format (also known as a parseab } \\
\text { text format). A file that describes and documents data used } \\
\text { the digital movie package, Mining activity in Nevada 1851- } \\
\text { 1995. }\end{array}$ \\
& $\begin{array}{l}\text { Federal Geographic Data Committee "frequently asked } \\
\text { questions" (FGDC FAQ) format. A file that describes and } \\
\text { documents data used in the digital movie package, Mining } \\
\text { activity in Nevada 1851-1995. }\end{array}$
\end{tabular}




\section{How to Run the Digital Movie}

In order to run the movie, Microsoft PowerPower 2000 (or newer version) application must be installed on the computer. Double click the file movie.ppt to open in PowerPoint, and then click the slide show icon on the bottom left of the PowerPoint screen to start the movie. You can right click the mouse anywhere on the screen and select end show from the context menu to end the movie at anytime. (Depending where you are within the movie you may need to select end show a couple of times to exit the movie and return to the PowerPoint screen.) The frame transition time can be adjusted according to your preferences or type of use by selecting Slide Transition under the Slide Show menu and adjusting the time entry. After the introductory frames of the movie, you are given a series of buttons to select from as follows: Mining activity in Nevada full length movie, Major mines 1860-1895 animation, Major mining districts 1860-1995 animation, Mineral production chart, and Links to decade time periods (fig.1). If you select an animation on the Movie Menu it will continue to loop until you select the Return to the Movie Menu button that appears at the end of the animation (fig. 2). If you select the Mineral production chart on the Movie Menu you will be directed to an animated mineral production chart and summary at the end of the movie followed by the Links to decade time periods frame and the Return to the Movie Menu button. If the return button is not selected, after a short pause you will be returned to the start of the movie automatically. The Links to decade time periods (fig. 3) button connects to the hyperlinks frame for each decade and allows you to view the series of frames for a particular decade. You can return to the time period link screen after viewing a decade by clicking the Return to time links (fig. 4) hyperlink at the bottom of the last frame of the series that displays the mining districts for that decade. If you make no selection on any menu, after a short pause, the full movie will automatically continue. 


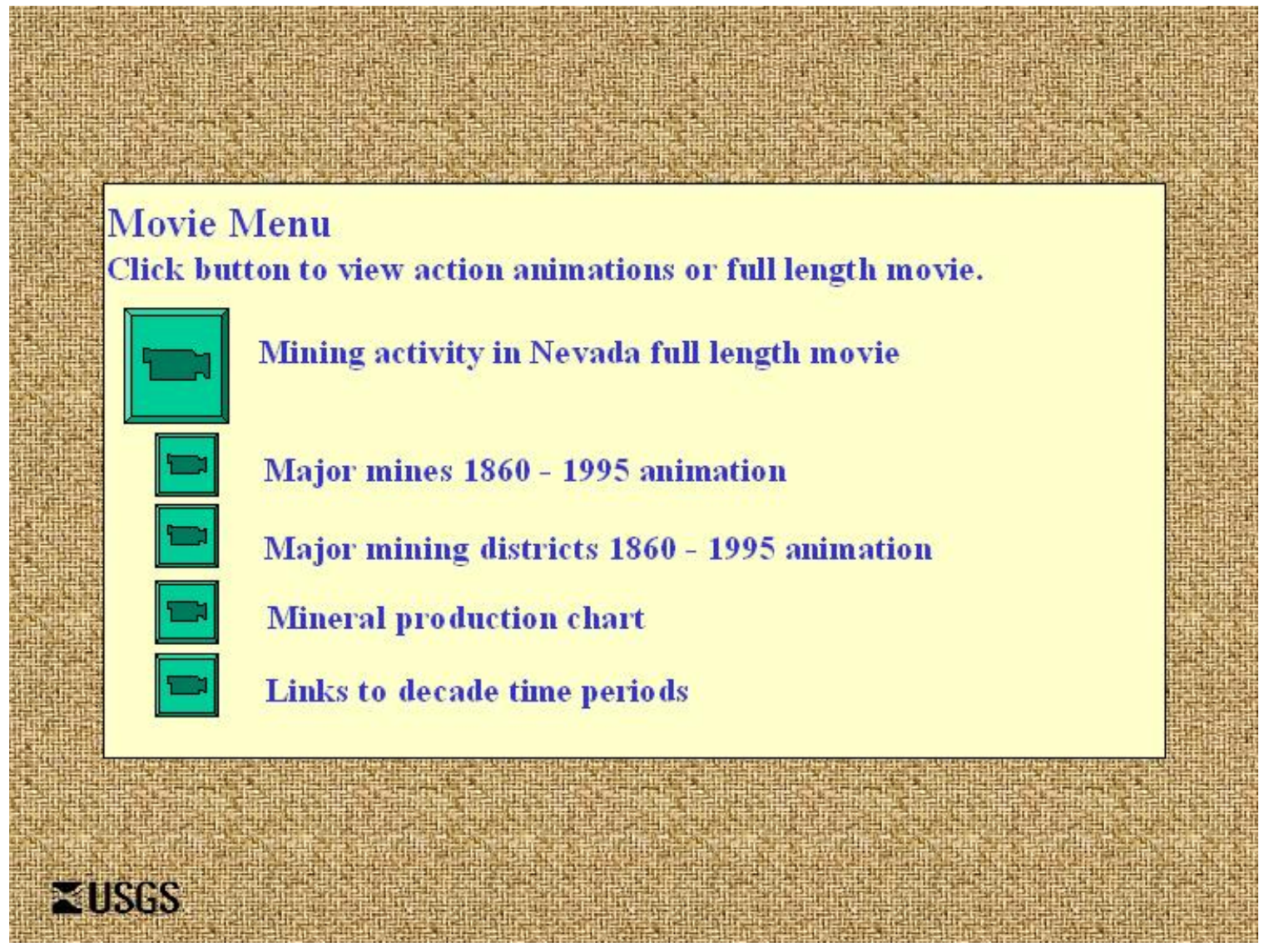

Figure 1. The movie selection menu appears after the introductory movie frames. 


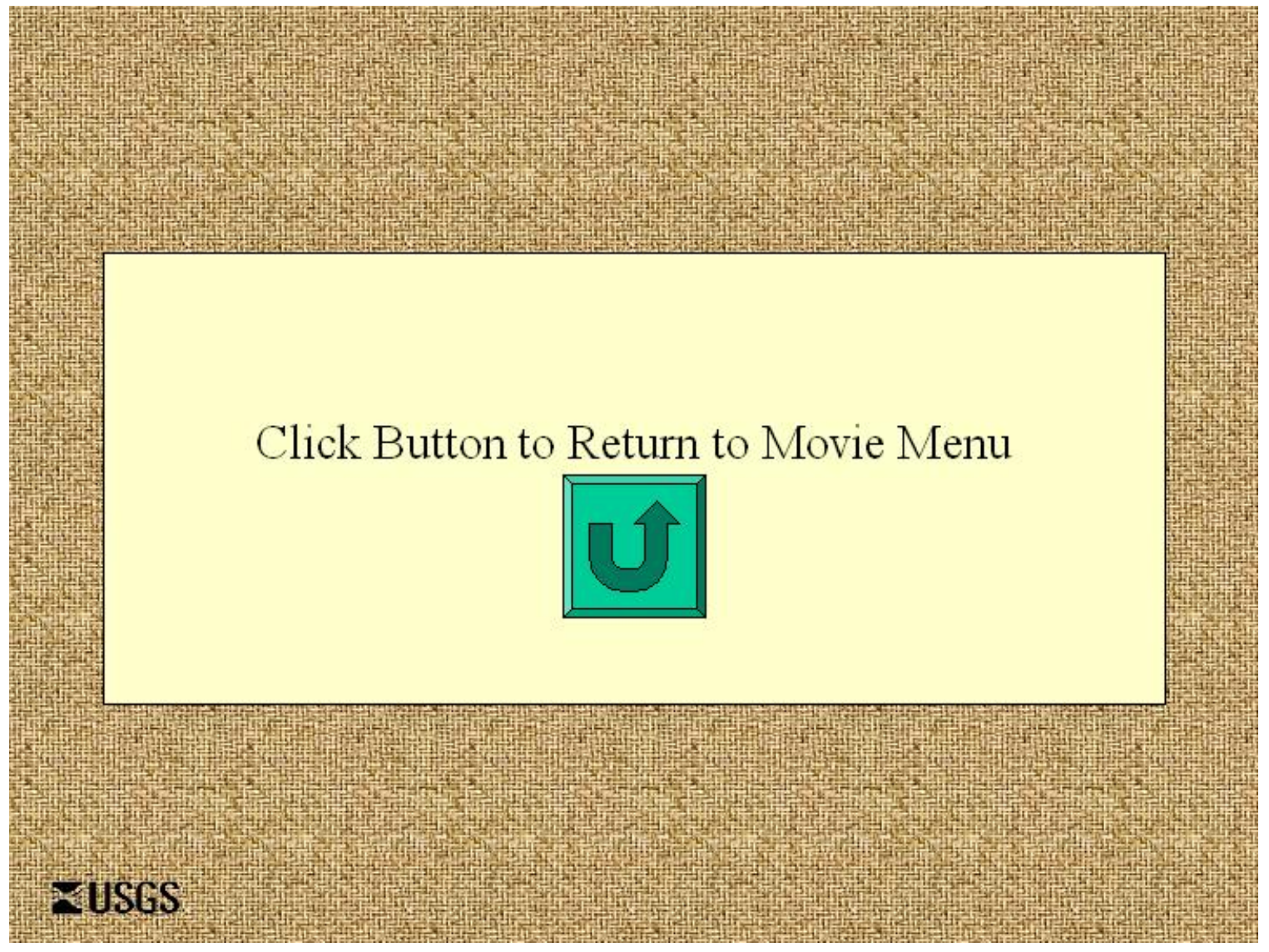

Figure 2. The return to the main movie button appears at the end of each short animation and at the end of the full length movie. 


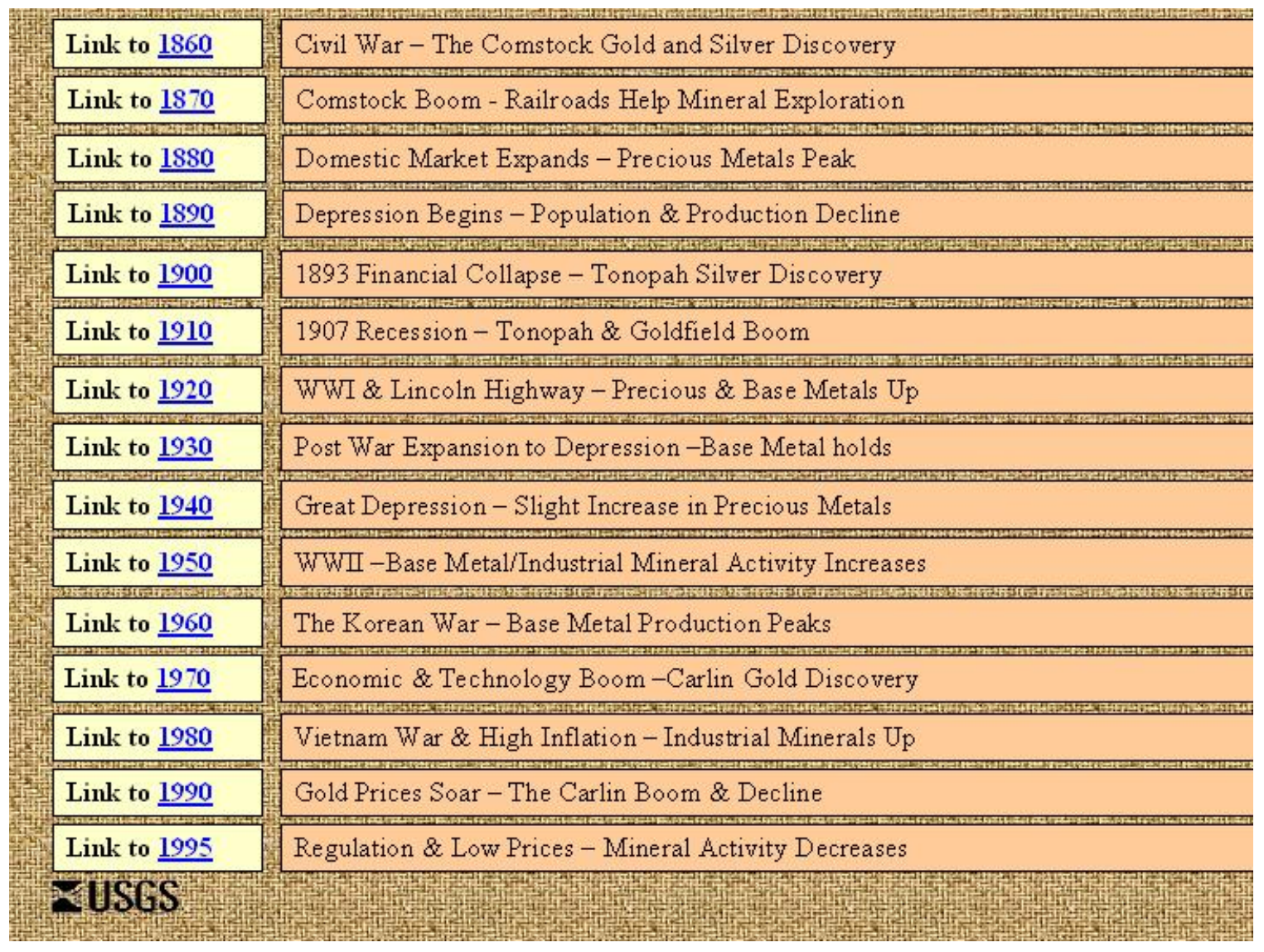

Figure 3. Links to time periods frame with decade hyperlinks and historical event captions. 


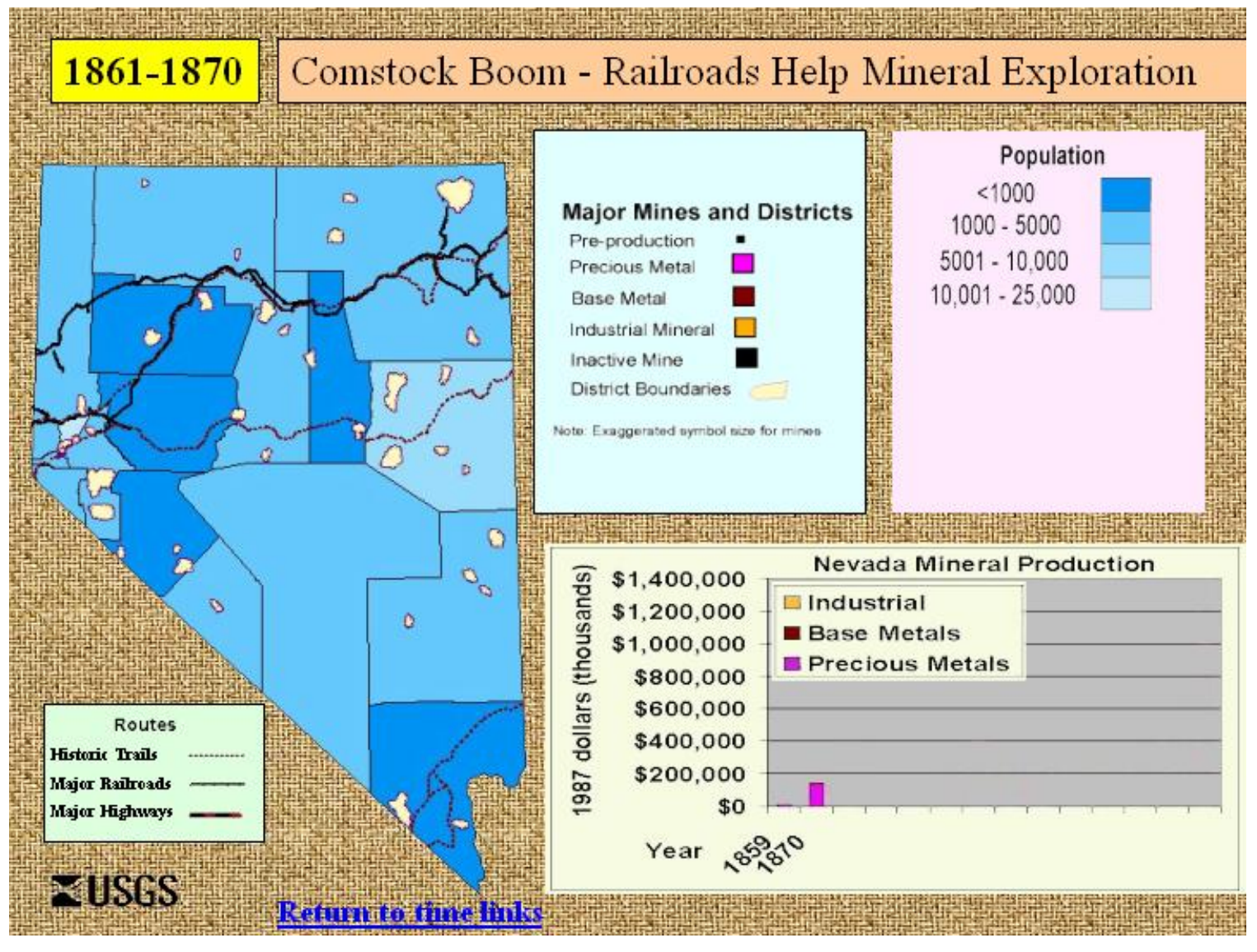

Figure 4. To return to the Links to decade time periods frame in the full length movie, click the Return to time links hyperlink at the bottom of the last frame of a decade series displaying the mining districts . 


\section{Symbolization, Legends, Charts and Frame Layout}

There are several legends in the movie package displaying the symbols for the major mines and mining districts, routes, and county population. Mines in pre-production status are marked with a black small square in the center of a larger colored-coded square, and the mines in production are symbolized with a color-coded square as follows: magenta for precious metal; brown for base metal; and gold for industrial mineral. Inactive mines are symbolized with a large black square, and the major mining districts are symbolized as yellow polygons with a purple border (fig.5). The population legend has up to ten categories ranging from a population of $<1000$ represented by dark blue to a population $>1,000,000$ represented by dark red. The Nevada county population changes by decade are represented by the shades of blue and red classified in the population legend (fig.6). The routes legend represents historic trails with a dashed line, major railroads with a hatched line, and major highways with a thicker line with alternating red and black colors (fig.7). For each decade a Nevada mineral production bar chart displays relative production values for industrial mineral (gold color), base metal (brown color) and precious metal (magenta color) (fig.8). A gold price chart was substituted for the mineral production chart in the last time period of 5 years from 1991-1995 because the significant rise and fall of the gold prices played an important role in the decreased mineral activity during this time (fig.9). A line chart of Nevada mineral production summarizes the total mineral production for the years 1859-1995 and displays the three major gold boom periods, the Comstock, the Tonopah-Goldfield, and the Carlin (fig.10). The movie frame layout includes a date header describing the decade and an event header describing a major historical event and mineral activity trend for that particular decade (fig.11). 


\section{Symbolization of}

Major Mines and Districts

Pre-production

Precious Metal

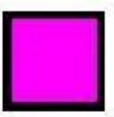

Base Metal

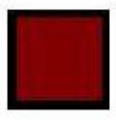

Industrial Mineral

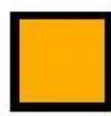

Inactive Mine

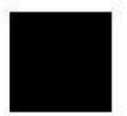

District Boundaries

Figure 5. Legend for the major mines and districts. The symbols for mines are exaggerated for viewing purposes and do not represent the size of the mine. 


\section{Population $<1000$ \\ $1000-5000$ \\ $5001-10,000$ \\ $10,001-25,000$ \\ $25,001-50,000$ \\ $50,001-100,000$ \\ $100,001-250,000$ \\ $250,001-500,000$ \\ $500,001-1,000,000$ \\ $>1,000,000$

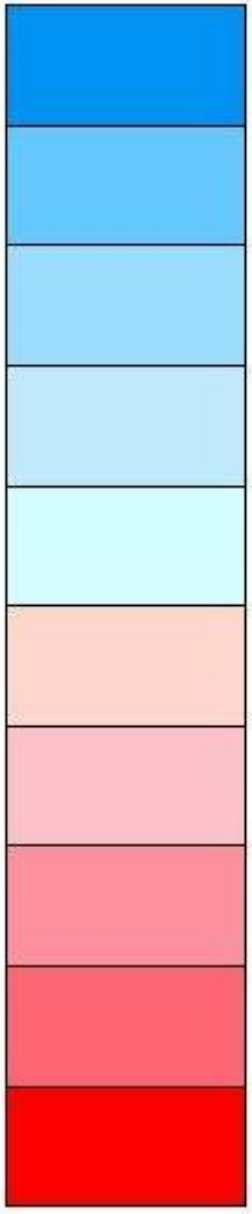

Figure 6. Color shade symbolization for county population range from blue to red. 


\section{Routes}

Higtoric Tr

Major figilrojd: $\longrightarrow$

Major Highwoys

Figure 7. Symbols for trails, railroads and highway routes. 


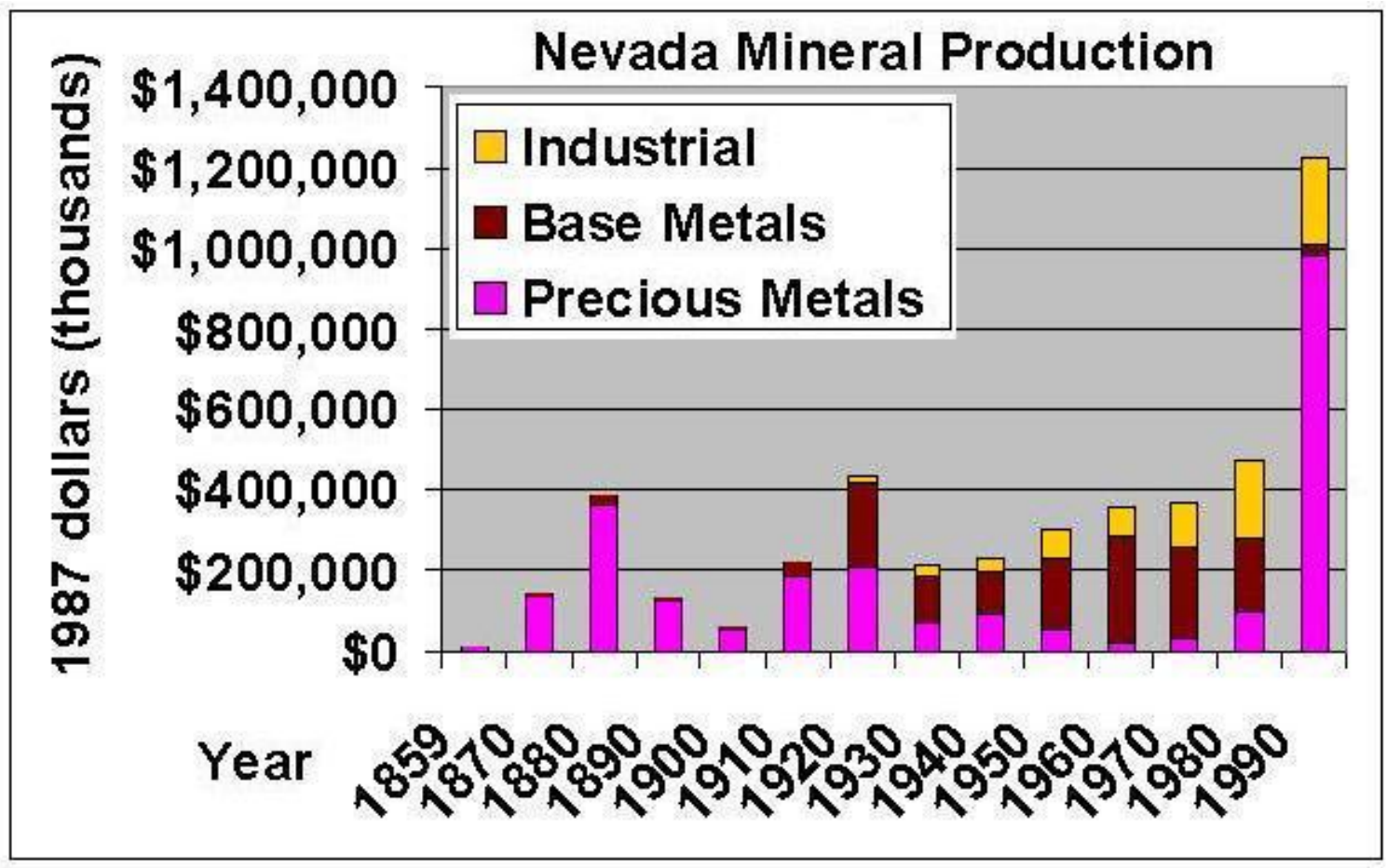

Figure 8. Production bar chart for industrial minerals, base metals, and precious metals by decade. 


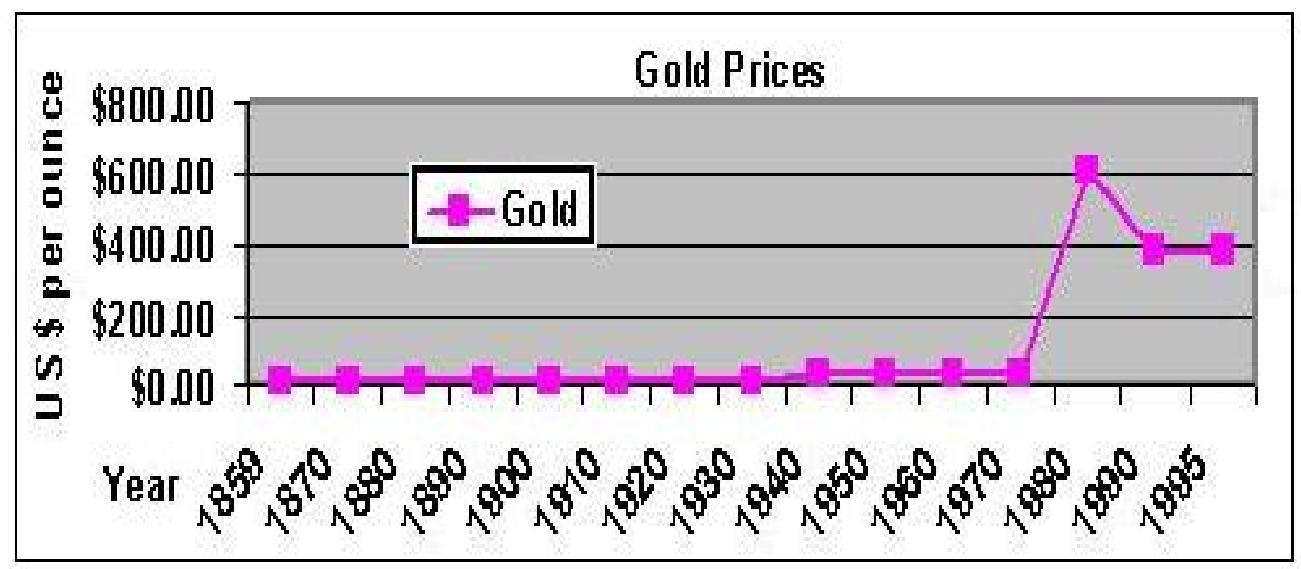

Figure 9. Gold prices displayed for the 1990-1995 time frame. 


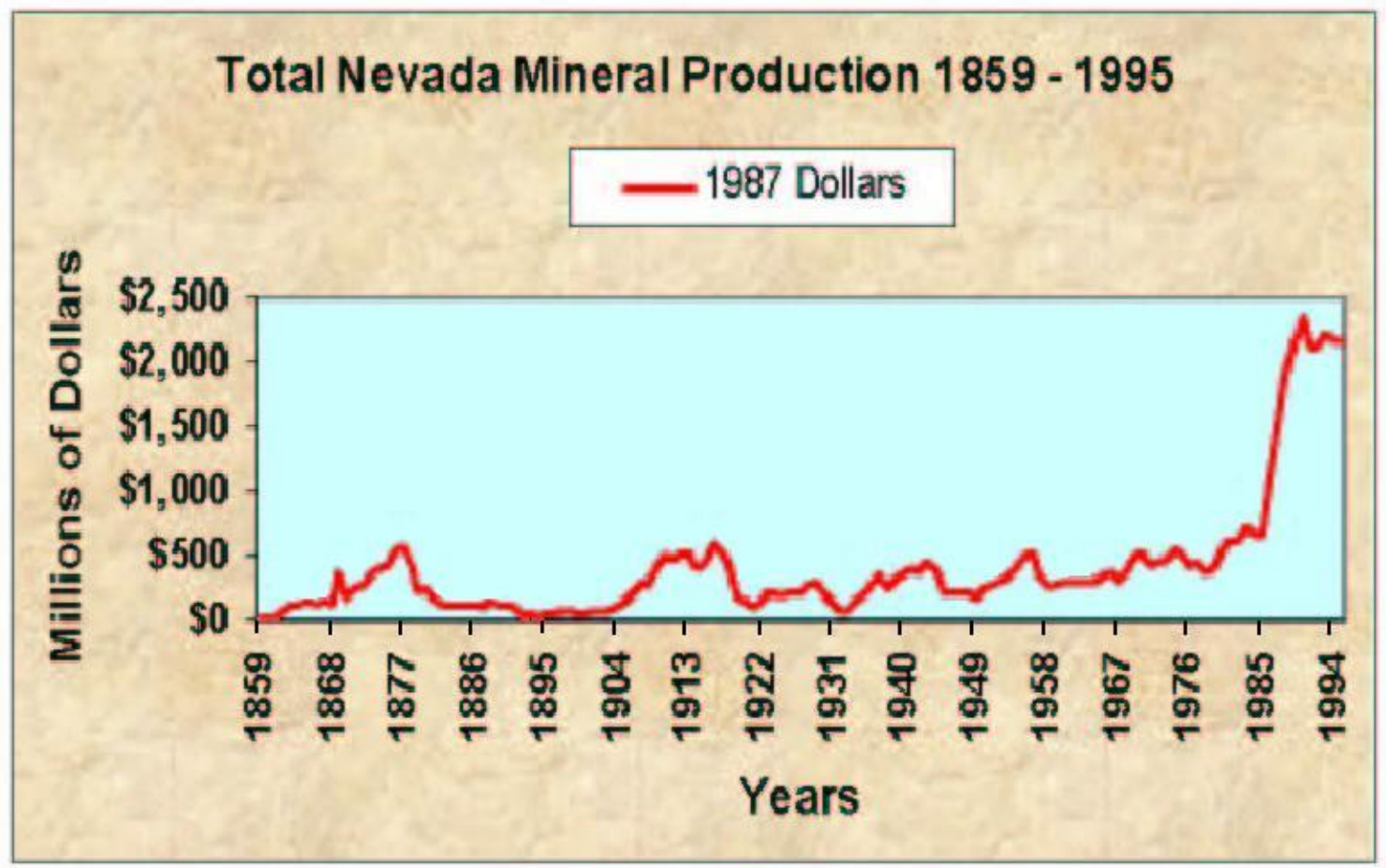

Figure 10. Summary chart of total Nevada mineral production for 1859 - 1995. 


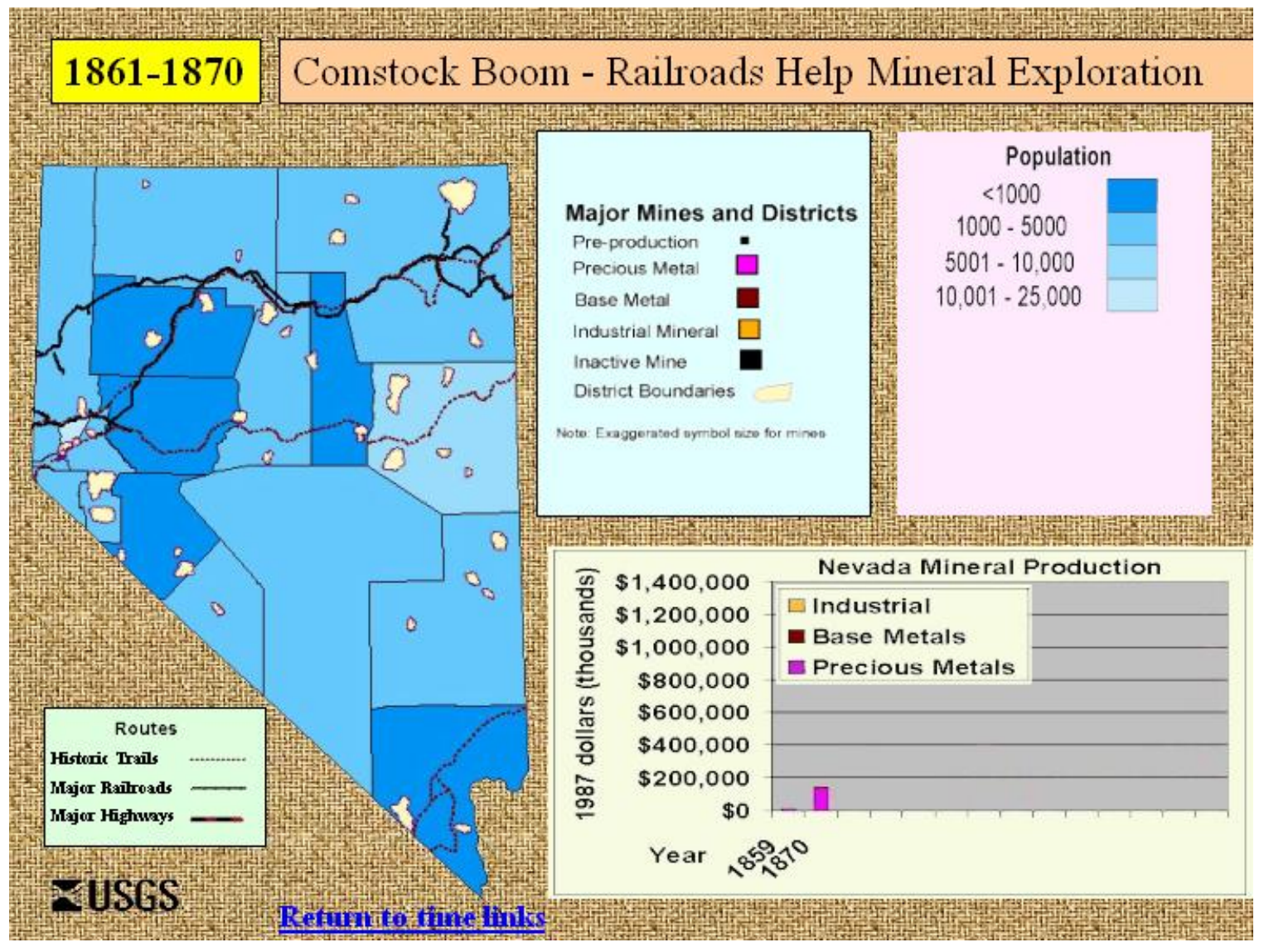

Figure 11. Example of frame layout with decade date header (top left) and historical event and mineral activity header. 


\section{Data Sources and Processing}

Data for significant Nevada precious metal and base metal deposits were extracted from the Excel spreadsheet SD4.xls (Long and others, 1998) and put into an Excel table sigdep.xls. Data fields included location, production, and date of discovery. Location data was used to create an event theme in ArcView 3.2 that was converted to the shapefile, sig_dep.shp. The spatial data was then sub-divided into several shapefiles representing decade intervals for the period 1851-1995, using the fields: DISC_YR (year of discovery); PROD_DATE (date of production start); PROD_END (date of production end); ACTIVE_MIN (active or inactive date). For this data, significant deposits were considered to be deposits that contain at a minimum of one of the following metals: 2 metric tons of gold, 85 metric tons of silver, 50,000 metric tons of copper, 30,000 metric tons of lead, or 50,000 metric tons of zinc.

Location, discovery dates, and production information for large industrial mineral occurrences in Nevada were extracted from the Mineral Resources Data System (MRDS) database and the Minerals Availability System/ Minerals Industry Location System (MAS/MILS) database provided in a FoxPro Version 2.6 format (McFaul and others, 2000). The MRDS data was queried using the field COMMOD (commodity type) and selecting industrial mineral types of occurrences, as well as the field DEP_SIZE (deposit size) $=\mathrm{L}$ (large). The location information was used to create an event theme that was converted to the shapefile, mrds_industrial.shp. The spatial data was then sub-divided into several shapefiles representing decade time intervals for 1851-1995 using the fields: YR_DISC (year of discovery); YR_1 $1^{\text {st }}$ PRO (year of first production); YR_LAST (year of last production). The MAS/MILS data (McFaul and others, 2000) was queried using the field COMMOD (commodity type) to select industrial mineral mines that had activity information. An event theme was created from the location data and converted to the shapefile, mils_industrial.shp. The spatial data was then sub-divided into several shapefiles representing decade time intervals for 1851-1995 using the fields YOD (year of discovery); YIP (year of initial production): and YLP (year of last production). The mineral deposit locations were then symbolized in ArcView 3.2 with a color-coded square for producing deposits (magenta = precious metal, brown = base metal, and gold = industrial mineral), a small black square in the middle of the color-coded square indicates a pre-production status, and a large filled black square indicates an inactive mine.

Tingley (1992) provided ArcView shapefiles ( version 3.x) imported (from ARC/INFO 7.1.2 E00 files) for Nevada mining districts, (mdist_p.shp), and major transportation routes in Nevada, (roads_a.shp). Corresponding mining districts for the mineral deposits were extracted from the mining district shapefile mdist_p (Tingley, 1992). The districts were subdivided into several shapefiles representing decade time intervals, and the polygons were symbolized with a pale yellow fill and purple border indicating the mining district boundary. The mining district layout was used at the end of each decade series as a general summary of mineral activity for that decade. Note that not every mineral deposit lies within or is represented by a mining district. 
Shapefiles for major highways (Tingley, 1992) and railroad routes (ESRI data, 2002) were available, however shapefiles for historic trails were not found. After some online research it was evident that the major trails closely resembled the major highway routes. The Old Spanish Trail became Interstate 15, the Immigrant Trail became Highway 80, and the Old Pony Express and stagecoach trail became Highway 50. The main roads were copied into a newly created trails shapefile. Two small diversions of the Old Spanish Trail and the immigrant trail and one on the Pony Express trail became minor roads that were copied from the roads shapefile into the trails shapefile. One small loop on the Eastern portion of the Pony Express trail was digitized on screen and added. The trails therefore are not highly accurate but are reasonably close representations and adequate for the digital movie purposes. The time periods assigned to the railroad routes are not accurate but are generalized to display the route development from the 1860's Transcontinental Railroad (Central Pacific routes) to the 1900's Southern Pacific and Northern Nevada routes. Background on Nevada mining history was provided by Tingley and others, 1993 .

Precious metal, base metal, and industrial mineral annual total production data 1859-1992 for Nevada (by district and by county) was provided by Tingley (unpub. data, 2003) in the file Au-Ag production 1849-1992.xls. These data were used to create an Excel line chart showing total Nevada mineral production in 1987 dollars. Microsoft Paint 5.1 software was used to slice the chart into JPEG images for animating the mineral production progression over time, as well as for summarizing and emphasizing the three major boom periods: the Comstock, the Tonopah-Goldfield, and the Carlin. The production data for precious metals, base metals and industrial minerals were also used to create bar charts by decade that shows the production rise and decline of the mineral types. The bars were color-coded to match the mineral occurrence color-coding used for the mines symbols and exported as JPEG images for the PowerPoint presentation.

Historical gold price data was obtained online from the National Mining Association (2003) and was imported into an Excel spreadsheet to create a gold price line chart that was exported to a JPEG image and used in the presentation to show the extraordinary increase in gold prices during the 1980s and the sharp decline in the 1990s.

Online historical census data (Reno, 2002) for Nevada Counties was used to show patterns in population changes by decade. Ten classifications representing the population range from $>1000$ to $>1,000,000$ were created. Shapefiles of county population were created for each decade with the counties color-coded and exported from an ArcView layout to JPEG images and inserted into the PowerPoint slides. ArcView shapefiles (version 3.x) for Nevada state (states.shp) and county (counties.shp) boundaries, and railroad system (rail100k.shp) were obtained from ESRI Data (2000). The "man in a hard hat image” was scanned from a Nevada mine visit photograph (Moyer, unpub. image, 2003) and was used as a visual enhancement to the movie text. 
The data was projected to UTM Zone 11 NAD 27 in ArcView 3.2 and layouts were created at a scale of 1: 5,474,178. The scale selection was based on the preferred size of the layout for the presentation. The presentation was created as a movie (movie.ppt) with text for educational purposes and as two short animations displaying the mining districts (districts +routes.ppt) and mine sites (mines + routes.ppt) that could be used for exhibit booth purposes.

\section{References}

Environmental Systems Research Institute, Inc. (ESRI), 2002, ESRI Data \& Maps: digital files, CD-ROM.

Long, K.R., DeYoung, Jr., J.H., Ludington, S.D., 1998, Database of significant deposits of gold, silver, copper, lead and zinc in the United States: U.S. Geological Survey Open-File Report 98-206B, Excel spreadsheet SD4.xls.

McFaul, E.J., Mason, Jr, G.T., Ferguson, W.B., Lipin, B.R., 2000, U.S. Geological Survey mineral databases - MRDS and MAS/MILS: U.S. Geological Survey Digital Data Series 52, CD-ROM.

Nevada Mining Association, 2003, Historical Gold Prices - 1833 to present: online data, http://www.nma.org/pdf/gold/his_gold_prices.pdf

Reno, Mona, 2002, Nevada county populations 1860 - 2000: Nevada State Library and Archives, online data: http://dmla.clan.lib.nv.us/docs/nsla/sdc/CountyPops/all_data.htm

Tingley, J.V., 1992, Mining Districts of Nevada ( ${ }^{\text {nd }}$ ed.): Nevada Bureau of Mines and Geology Report 47, digital files, scale 1:1,000,000, CD-ROM.

Tingley, J.V., Horton, R.C., Lincoln, F.C., 1993, Outline of Nevada mining history: Nevada Bureau of Mines and Geology Special Publication 15, 47 p. 